\title{
A LOCUÇÃO PROFERIDA PELO DIRECTOR DO INSTITUTO UNIVERSITÁRIO DE DESENVOLVIMENTO E PROMOÇÃO SOCIAL
}

Conheci Monsenhor Celso Tavares da Silva numa já distante tarde de Outono de 1985 aquando de uma reunião realizada, em Coimbra, na Residência Padre Manuel da Nóbrega, no decurso da qual houve uma fecunda discussão sobre o projecto, então em preparação, hoje, felizmente, uma consoladora realidade, de criação do Instituto Universitário de Desenvolvimento e Promoção Social.

Nessa reunião, da qual conservo gratificantes recordações, participaram S. Ex. ${ }^{a}$ Rev. ${ }^{\text {ma }}$ o Senhor D. José Pedro da Silva, ao tempo Bispo de Viseu, o Professor Júlio Fragata, Monsenhor Celso e nós próprios.

Tratava-se de discutir o projecto de lançamento do I.U.D.P.S., que viria a ser concretizado em 1986 pelo Conselho Superior da Universidade Católica Portuguesa. A reunião tinha sido convocada pelo Senhor D. José Pedro da Silva para estudar o lançamento do Instituto e a organização do curso de licenciatura em Gestão e Desenvolvimento Social, e congregava três personalidades que tinham contribuído, inegavelmente, entre outras, para a criação do Centro Regional de Viseu, e que é da mais elementar justiça mencionar.

Em primeiro lugar, S. Ex. ${ }^{a}$ Rev. ${ }^{\text {ma }}$ o Senhor D. José Pedro da Silva, que contribuíra decisivamente para que a Universidade Católica instituísse, em Viseu, em 1980, um Centro Regional, que ministrava, desde esse ano, o Curso de Humanidades.

Foi ao Senhor D. José Pedro da Silva que, por parte da Diocese, ficou Viseu a dever a instalação do ensino universitário, primeiro, com o sobredito Curso de Humanidades e, em 1986, com a criação da licenciatura em Gestão e Desenvolvimento Social, que concretizou o projecto de um Curso voltado para a gestão dos recursos humanos e do desenvolvimento social.

Em seguida, a presença do Professor Júlio Fragata, então Director da Faculdade de Filosofia, da Universidade Católica Portuguesa, a quem muito ficou a dever-se o desenvolvimento do Curso de Humanidades, que acompanhou de perto no seu funcionamento nos primeiros anos, com a inteligência, o empenhamento e 
a notável capacidade de trabalho que eram reconhecidas àquela notável figura do pensamento filosófico português, de universitário e de sacerdote jesuíta.

Por último - the last, but not the least -, Monsenhor Celso Tavares da Silva, na sua qualidade de Secretário-Geral do Centro Regional de Viseu da UCP. Três eminentes figuras que, conjuntamente com outras - , como as do Senhor Reitor Honorário Professor Bacelar e Oliveira e do Senhor Professor Lúcio Craveiro da Silva, para citar neste momento os professores da Universidade Católica já jubilados - contribuíram decisivamente para a instalação e o desenvolvimento do ensino universitário neste distrito do Centro Interior.

Foi nessa reunião de há quase uma década que, por parte da Diocese, ficou assente a minha colaboração com a Universidade Católica, que, ao longo destes anos, muito me tem honrado e a que tenho procurado corresponder na medida das minhas capacidades.

Voltando a Monsenhor Celso, foi essa reunião a primeira de muitas outras em que ambos participámos, ao longo destes anos em que tive — posso afirmá-lo sem que se trate de qualquer figura de retórica - o privilégio de com ele contactar.

De facto, depois de, em 1986, o Instituto ter sido criado, sendo a primeira Faculdade deste Centro Regional, e de termos sido nomeado, por Sua Eminência o Magno Chanceler, Presidente da então Comissão Científica, estabeleceu-se entre Monsenhor Celso e nós próprios uma estreita colaboração por virtude das funções que já exercia e daquelas para que fomos mandatado.

Colaboração tão frutuosa, e num clima de excelente entendimento, que foi com plena justificação que, em 1989, já com S. Ex. ${ }^{a}$ Rev. ${ }^{\text {mo }}$ o Senhor D. António Monteiro como Bispo de Viseu e S. Ex. ${ }^{\text {a }}$ Rev. ${ }^{\text {ma }}$ o Senhor Professor Doutor D. José da Cruz Policarpo no exercício das funções de Reitor da Universidade Católica, entendi ser meu dever propor Monsenhor Celso para integrar o Conselho de Direcção do Instituto.

No decurso destes últìmos anos, a colaboração existente entre nós aprofundou-se consideravelmente, constituindo uma das mais gratificantes recordações que guardo do exercício do cargo de Director do Instituto. Cooperante, leal, incansável no apoio prestado, Monsenhor Celso foi, durante este período importante do desenvolvimento do Instituto, o meu braço direito, como sabem todos os que contactavam connosco mais de perto.

Mantendo-me sempre ao corrente do que se passava no Instituto, Monsenhor Celso desenvolveu uma notável actividade como membro do Conselho de Direcção e Secretário-Geral do Centro Regional de Viseu da Universidade Católica Portuguesa. O seu conhecimento do meio de Viseu, o seu carisma, o prestígio de que disfrutava - e disfruta - nesta cidade, o seu empenhamento, bem como a sua eficiência contribuíram em muito para tornar menos difícil o meu mandato de Director e de Presidente do Conselho Científico do Instituto. 
As suas intervenções nas reuniões do Conselho de Direcção, a sua capacidade de diálogo e de concertação nas relações com os estudantes e os funcionários, bem como com entidades externas à Universidade, a sua prudência e comedimento constituíram qualidades que todos os que com ele temos tido ensejo de privar pudemos apreciar.

Não poderemos esquecer o papel relevante que teve na fase de candidatura aos Programas PEDIP e PRODEP, bem como na fase de realização das obras e de apetrechamento deste belo edifício em que nos encontramos.

Com o seu entusiasmo e com a força interior inquebrantável que o anima, Monsenhor Celso participou, com os outros membros do Conselho de Direcção e com uma equipa muito dinâmica, na preparação da candidatura aos Programas Comunitários supramencionados, que o Instituto ganhou, bem como a Faculdade de Ciências Económicas e Empresariais e a Faculdade de Filosofia de Braga, sob a inteligente e dinâmica direcção, respectivamente, do Professor Xavier Pintado e do Professor Lúcio Craveiro da Silva.

Mas a sua colaboração, rica e diversificada, prosseguiu, incansavelmente, nos concursos para adjudicação das obras, na concretização do projecto, nos contactos com entidades administrativas e com as empresas de construção que, em tempo record, dotaram este Centro Regional deste edifício, sem o qual seria impensável o desenvolvimento da Universidade Católica em Viseu, dadas as insuficiências do edifício existente e o aumento da população escolar.

No exercício das suas funções na Universidade Católica, Monsenhor Celso confirmaria uma carreira marcada pelo Serviço de Deus e da Igreja e por qualidades profissionais e pessoais dignas de registo.

Seja-nos permitido referir, neste lugar, os aspectos essenciais do currículo do nosso homenageado.

Natural da freguesia de Cedrim, concelho de Sever do Vouga, o percurso de vida de Monsenhor Celso tem estado indissociavelmente ligado ao desta Diocese e distrito.

Com efeito, foi no Seminário Maior de Viseu que, em 1938, com apenas 22 anos, completou, com a informação final de 16 valores, o Curso de Teologia.

Enquanto aguardava a idade para tomar ordens, exerceu as funções de prefeito no Seminário Menor de Fornos de Algodres.

A sua ordenação sacerdotal ocorreu a 30 de Abril de 1939, tendo sido, no final desse já distante ano, nomeado pároco da freguesia de Santiago de Besteiros, concelho de Tondela, onde se manteve até 1953, ano em que transitou para a paróquia da vila de Oliveira de Frades, exercendo, cumulativamente, o cargo de arcipreste da respectiva área. Permaneceu naquele concelho do distrito de Viseu durante quinze anos, no decurso dos quais dedicou particular atenção à promoção social dos seus paroquianos, de modo especial, dos jovens. Neste sentido, criou cursos de formação familiar, orientados por Assistentes Sociais e organizou a 
Associação "Pró-Oliveira de Frades", a "Mútua de Gado", tendo, também, fundado o Externato Lafonense, de que foi professor e director.

Em 1968, foi nomeado por S. Ex. ${ }^{a}$ Rev. ${ }^{\text {ma }}$ o Senhor D. José Pedro da Silva Vice-Reitor do Seminário Maior, funções que exerceu até 1977, ano em que passou a Reitor da mesma instituição, pelo período de onze anos, tendo-as cessado, a seu pedido, em 1988, para poder dedicar-se mais intensamente - se é possível introduzir gradações quantitativas numa actividade exercida com inexcedível zelo e dedicação - ao Centro Regional de Viseu da Universidade Católica, de que era Secretário-Geral desde 1980.

A sua vocação pedagógica concretizou-se no exercício das funções de professor de Antropologia e de Arqueologia e História de Arte no Seminário Maior, bem como na regência da disciplina de História de Arte ao Centro Regional de Viseu.

Neste Centro, integra a Comissão Administrativa, além de ter exercido, como já referimos, as funções de Secretário-Geral e de Membro do Conselho de Direcção do Instituto Universitário de Desenvolvimento e Promoção Social.

A sua actividade alargou-se, também, a outros sectores, exercendo as funções de Director do Jornal da Beira, órgão oficioso da Diocese, de Presidente da Comissão Diocesana de Arte Sacra, de Director do Museu de Arte Sacra e membro do Conselho Diocesano de Pastoral.

Em 1973, foi nomeado Cónego Capitular da Sé de Viseu, tendo sido, posteriormente, agraciado pela Santa Sé com o título de Monsenhor.

Interessado, desde muito jovem, pela Arqueologia, tem participado em múltiplos congressos e jornadas da especialidade, com a apresentação de algumas comunicações de reconhecido interesse. Devidamente credenciado, dirigiu várias campanhas de escavações, umas da sua exclusiva responsabilidade e outras de colaboração com arqueólogos nacionais e estrangeiros. Neste domínio, assumem particular interesse as que realizou no castro de Baiões, cujo espólio constitui hoje um ponto de referência para o estudo do Bronze Final, frequentemente citado a nível peninsular e, mesmo, europeu.

Ainda no domínio da Arqueologia, ocupou-se, de modo especial, do estudo da Arte Rupestre, na área de Viseu, encontrando-se o seu nome inserido no livro WHO'S WHO IN ROCK ART, editado pelo "Centro Camuno di Studi prehistorici" - Itália. Trata-se de uma espécie de dicionário bibliográfico de especialistas e técnicos a nível mundial, no qual figuram apenas sete nomes de portugueses.

É autor de diversos estudos, de que destacamos:

- Vestígios pré-históricos de Besteiros, I e II;

- Gravuras Inéditas da Beira Alta;

- Contribuição para o estudo da cultura castreja na Beira Alta;

- «A arte rupestre da região do Vouga e a problemática da sua cronologia»,-in Os Portugueses no Mundo - conferência internacional. 
Em co-auditoria, publicou:

- Gravuras e inscrições rupestres da região de Viseu;

- Castro de Cárcoda,I e II;

- Catálogo da colecção arqueológica Dr. José Coelho;

- Depósito de Fundidor do Final da Idade do Bronze do Castro da Senhora da Guia (Baiões, S. Pedro do Sul, Viseu);

- Gravuras rupestres de Santa Bárbara (Ribafeita, Viseu).

Além dos trabalhos que acabámos de mencionar, Monsenhor Celso tem proferido, com grande capacidade comunicacional, múltiplas conferências, nomeadamente em Lisboa, no Porto, em Viseu, em Oliveira de Frades e no seu concelho de origem - Sever do Vouga.

O seu curriculum vitae é ainda enriquecido com a sua afiliação em diversas sociedades científicas, como a:

- Associação dos Arqueólogos Portugueses;

- Sociedade Portuguesa de Antropologia e Etnologia da Faculdade de Ciências da Universidade do Porto;

- Associação Portuguesa de Museologia;

- Grupo de Arqueologia do Porto (de que é sócio honorário)

- Centro de Estudos Pré-históricos da Beira Alta e Centro Camuno di Studi prehistorici - Itália.

A enumeração dos aspectos mais relevantes do curriculum vitae de Monsenhor Celso Tavares da Silva permite-nos inferir estarmos em presença de uma das mais notáveis figuras da Diocese de Viseu.

Sacerdote exemplar, pedagogo competente e dotado de excelente relacionamento com os seus alunos, gestor universitário marcado pelo entusiasmo que põe em todos os seus actos e pela eficácia das suas funções, espírito de artista e arqueólogo com obra firmada, Monsenhor Celso Tavares da Silva é muito justamente homenageado pela Universidade Católica Portuguesa pelo contributo notável que deu à institucionalização do Centro Regional de Viseu e ao desenvolvimento do Instituto Universitário de Desenvolvimento e Promoção Social.

Unindo a minha voz à de todos os docentes e membros do Conselho de Direcção do Instituto, exprimo-lhe, caríssimo Monsenhor, o mais sincero reconhecimento por tudo o que lhe devemos e reafirmo-lhe a nossa maior admiração e estima. 